\title{
Delayed Spontaneous Cerebrospinal Leak through Clival Recess: Emphasis on Technique of Repair
}

\author{
${ }^{1}$ Satyawati Mohindra, ${ }^{2}$ Sandeep Mohindra, ${ }^{3}$ Kiran Joshi, ${ }^{4}$ Harsimrat S Sodhi
}

\begin{abstract}
Objective: To report a rare case of delayed spontaneous cerebrospinal fluid (CSF) leak through clival region in the sphenoid sinus.
\end{abstract}

Case report: A 35-year-old female presented to our outdoor clinic with watery right nasal discharge for past 2 months, which increased on bending forward. Her medical history, general physical and neurological examinations were unremarkable. High-resolution computed tomographic scan and magnetic resonance cisternography were performed and suggestive of defect in right cribriform plate and right sphenoid sinus. Endoscopic repair was done but same symptoms occurred after 1 month. Repeat magnetic resonance imaging showed fistula in the lateral wall of right sphenoid sinus. Revision endoscopic transnasal CSF rhinorrhea repair was done. Lumbar subarachnoid drain was left in place for 5 days. No recurrence was noted at 12 -week follow-up.

Conclusion: Endoscopic transnasal approach is the best modality of treatment for midline skull base defects. Delayed leaks can present from previously weak areas and all the doubtful areas must be examined during surgery.

Keywords: Clival recess, Endoscopic repair, Spontaneous cerebrospinal fluid leak.

How to cite this article: Mohindra S, Mohindra S, Joshi K, Sodhi HS. Delayed Spontaneous Cerebrospinal Leak through Clival Recess: Emphasis on Technique of Repair. Clin Rhinol An Int J 2017;10(1):42-44.

\section{Source of support: $\mathrm{Nil}$}

Conflict of interest: None

\section{INTRODUCTION}

Idiopathic spontaneous cerebrospinal fluid (CSF) leak occurs without any identifiable cause. ${ }^{1,2}$ These patients

\footnotetext{
${ }^{1}$ Additional Professor, ${ }^{2}$ Associate Professor, ${ }^{3}$ Senior Resident ${ }^{4}$ Assistant Professor

${ }^{1,3}$ Department of Otolaryngology, Head and Neck Surgery Postgraduate Institute of Medical Education \& Research Chandigarh, India

${ }^{2,4}$ Department of Neurosurgery, Postgraduate Institute of Medical Education \& Research, Chandigarh, India

Corresponding Author: Kiran Joshi, Senior Resident Department of Otolaryngology, Head and Neck Surgery Postgraduate Institute of Medical Education \& Research Chandigarh, India, Phone: +919417809675, e-mail: dr.kiranjoshi23@gmail.com
}

usually present with clinical feature and imaging characteristic of raised intracranial pressure like empty sella syndrome $(80 \%),)^{3,4}$ arachnoid pits $(63 \%)$, and a thinned skull base. Multiple skull base defects are seen on computed tomography (CT) of $31 \%$ patients. ${ }^{5}$ Generally, spontaneous CSF leak patients are middle-aged fatty women. ${ }^{6}$ Spontaneous CSF rhinorrhea can occur at cribriform plate, ethmoid sinus, frontal, and sphenoid sinus. However, primary spontaneous CSF leak from clival defect is extremely rare. Here, we describe a case of spontaneous CSF rhinorrhea through clival region defect, which was repaired using endoscopic endonasal transsphenoidal technique. The aim of this study is to discuss the etiology of the defect at this very rare location.

\section{CASE REPORT}

A 35-year-old female presented to our outdoor clinic with watery discharge from the right nostril for past 2 months, which increased on bending forward. Her medical history was unremarkable. Her general physical and neurological examinations were unremarkable. The glucose concentration of the fluid was compatible with CSF. There was no evidence of trauma or increased intracranial pressure. Ophthalmological examinations ruled out papilledema and field defect.

Standard high-resolution CT scan (Figs 1A to E) was performed, which revealed the defect in right cribriform plate and soft tissue density in right lateral recess of sphenoid sinus. Magnetic resonance cisternography showed $\mathrm{T} 2$ hyperintense signal in right cribriform plate and right sphenoid sinus (Figs 2A and B ). No evidence of benign intracranial hypertension was seen. On endoscopic transnasal approach, the defect was found in right cribriform plate with active and profuse CSF leakage. It was closed with fat, fascia, rotated middle turbinate, and glue. Examination of sphenoid revealed collected CSF but no active leak or defect was visible even on Valsalva maneuver. Pack was removed on 5th day. Immediate postoperative period was uneventful.

The same symptoms recurred after 1 month. Repeat magnetic resonance imaging (MRI) showed fistula in the lateral wall of right sphenoid sinus (Fig. 2C). A revision endoscopic transnasal CSF rhinorrhea repair was done. Previous repair site did not show any leak. Sphenoid 


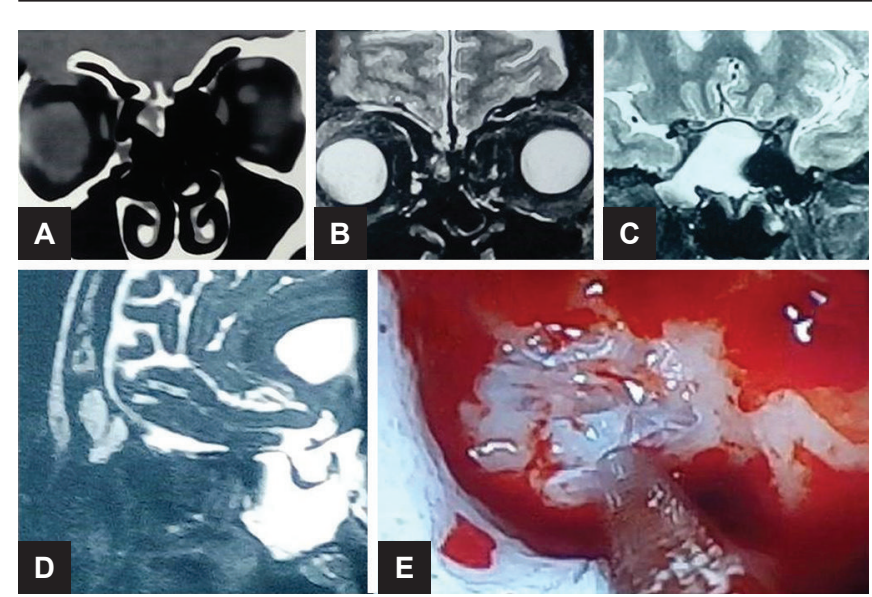

Figs 1A to E: (A) Coronal section of CT of nose and paranasal sinuses showing a soft tissue density through right cribriform plate; (B) T2-weighted MRI, coronal cut suggestive of CSF egressing through right cribriform plate; (C) T2-weighted MRI, coronal cut at the level of sphenoid sinus showing hyperintense right sphenoid sinus; (D) T2-weighted MRI, sagittal section showing a hyperintense shadow in the sphenoid sinus, with a communication with prepontine subarachnoid space; and (E) endoscopic picture of the clival recess of sphenoid sinus, showing multiple areas permitting CSF leakage. An arachnoid outpouching can also be seen

sinus was filled with CSF. After stripping the mucosa from posterior wall, a high pressure leak was observed through multiple sites and a small arachnoid outpouching on posterior wall of sphenoid sinus in the region of clivus (Fig. 2A).

Initial attempts of plugging with fat failed, due to high CSF pressure. So, lumbar drain was put and multiple defects plugged with fat. It was reinforced with muscle, fascia, rotated septomucosal flap, and fibrin glue. Lumbar subarachnoid drain was left in place for 5 days. Pack was kept for 5 days and the patient was discharged on 7th day. Check endoscopy at 12 weeks showed a healed posterior wall of the sphenoid (Fig. 2B).

\section{DISCUSSION}

Spontaneous CSF leak comprises approximately 3\% of all CSF leaks. The nontraumatic normal pressure variety is even rare. ${ }^{7} \mathrm{O}^{\prime}$ Connell ${ }^{8}$ subdivided spontaneous CSF leak into: Primary spontaneous, when there is no cause and secondary spontaneous, when a cause can be found. Tumors and hydrocephalus are important causes of secondary spontaneous leak. However, Ommaya ${ }^{9}$ believed that all spontaneous CSF leak should have a cause. He subdivided it into two categories: "High pressure," usually caused by tumors and hydrocephalus, and "low pressure," caused by congenital abnormalities, osteomyelitis, focal atrophy, and so on.

Psaltis et al ${ }^{10}$ reported spontaneous CSF leak account for $40 \%$ of fistulas in which cribriform plate $(52.7 \%)$ and sphenoid sinus (30.2\%) were the common sites. Among patients with sphenoid localization, spontaneous CSF
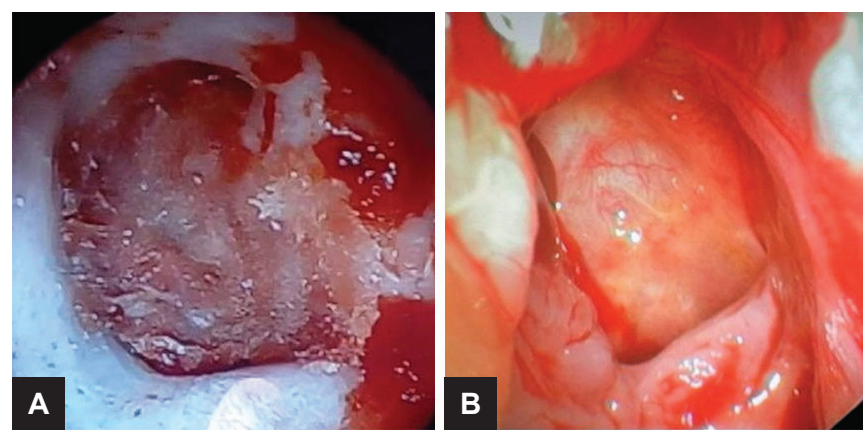

Figs 2A and B: (A) Endoscopic picture of the clival recess of sphenoid sinus, showing stoppage of CSF after fat plug-in achieved after opening the lumbar drain; and (B) endoscopic picture of the clival recess at 3 months follow-up. A well-epithelialized sphenoid sinus can be seen. A part of septomucosal flap can also be visualized inferiorly

leak arising from prepontine cistern through the clivus is extremely rare. In a recently published case series of 37 patients on spontaneous CSF leak, no patient had clival leak. ${ }^{11}$ However, we did not find any report where clival leak presented in a delayed manner after repair of another more obvious defect as in our case.

In our patient, the clivus was like a sieve with multiple defects permitting the leakage of CSF into the sphenoid. One of the defects also showed an arachnoid pouching. Similar findings of sieve-like defect in clivus were lacking in the present literature. However, Conboy et $\mathrm{a}^{12}$ reported a rare case of generalized erosion of the skull base with spontaneous CSF leak, which was complicated by herniation of the right temporal lobe into the sphenoid sinus.

Coiteiro et $\mathrm{al}^{1}$ reported two cases of idiopathic spontaneous leak through the clivus that they attributed either to a continuously pulsating effect of the basilar artery or to an intracranial pressure increase in a patient who underwent repeated Valsalva maneuver. However, an endoscopic approach was not used for leakage repair.

Kaufman et $\mathrm{a}^{13}$ described that normally occurring elevations in intracranial pressure could lead to CSF leakage through the middle fossa. The same mechanism also explains the occurrence of CSF leak in our patient where the CSF pressure was normal and MRI findings were not suggestive of benign intracranial hypertension (BIH).

Various techniques of repair have been described in the literature like transcranial and endoscopic. ${ }^{10}$ Among endoscopic techniques, transethmoidal-transsphenoidal vs transseptal-transsphenoidal are described. There is also a comparison of single-layer vs multiple-layer repair. We carried out endonasal endoscopic repair via transseptal transsphenoidal route. After denuding the mucosa of sphenoid sinus, the leak could be seen in the posterior wall.

An attempt to plug-in with fat was unsuccessful till we opened the lumbar drain. We widened the sphenoid 
ostium inferiorly and medially to give length to the nasoseptal flap which could then be placed over the multilayer repair. Our results have been successful and the patient is doing well at 12 weeks follow-up.

\section{CONCLUSION}

Spontaneous clival CSF leak is an uncommon condition. Clival CSF leak may occur due to intracranial malformation, hyperpneumatized sphenoid sinus, and raised intracranial pressure. An endonasal endoscopic approach has become the gold standard for the repair of midline skull base defects. Though our patient was a middle-aged obese female, there was no finding suggestive of BIH. Her initial outcome is successful, but long-term follow-up is required.

\section{REFERENCES}

1. Coiteiro D, Tavora L, Antunes JL. Spontaneous cerebrospinal fluid fistula through the clivus: report of two cases. Neurosurgery 1995 Oct;37(4):826-828.

2. Wise SK, Schlosser RJ. Evaluation of spontaneous nasal cerebrospinal fluid leaks. Curr Opin Otolaryngol Head Neck Surg 2007 Feb;15(1):28-34.

3. Goddard JC, Meyer T, Nguyen S, Lambert PR. New considerations in the cause of spontaneous cerebrospinal fluid otorrhea. Otol Neurotol 2010;31(6):940-945.
4. Kutz JW Jr, Husain IA, Isaaacson B, Roland PS. Management of spontaneous cerebrospinal fluid otorrhea. Laryngoscope 2008 Dec;118(12):2195-2199.

5. Schlosser RJ, Bolger WE. Management of multiple spontaneous nasal meningoencephaloceles. Laryngoscope 2002 Jun;112(6):980-985.

6. Wang EW, Vandergrift WA 3rd, Schlosser RJ. Spontaneous CSF leaks. Otolaryngol Clin North Am 2011 Aug;44(4): 845-856.

7. Beckhardt RN, Setzan M, Carras R. Primary spontaneous cerebrospinal fluid rhinorrhoea. Otolaryngol Head Neck Surg 1991 Apr;104(4):425-432.

8. O'Connell JF. Primary spontaneous cerebrospinal fluid rhinorrhoea. J Neurol Neurosurg Psychiatry 1964;27:241-246.

9. Ommaya AK. Cerebrospinal fluid rhinorrhoea. Neurology 1964;14:106-113.

10. Psaltis AJ, Schlosser RJ, Banks CA, Yawn J, Soler ZM. A systematic review of the endoscopic repair of cerebrospinal fluid leaks. Otolaryngol Head Neck Surg 2012 Aug;147(2):196-203.

11. Pagella F, Pusateri A, Matti E, Zoia C, Benazzo M, Gaetani P, Cazzador D, Volo T, Borsetto D, Emanuelli E. Endoscopic management of spontaneous clival cerebrospinal fluid leaks: Case series and literature review. World Neurosurg 2016 Feb;86:470-477.

12. Conboy PJ, Johnson IJ, Jaspan T, Jones NS. Idiopathic diffuse erosion of the skull base presenting as cerebrospinal fluid rhinorrhoea. J Laryngol Otol 1998 Jul;112(7):679-681.

13. Kaufman B, Yonas H, White RJ, Miller CF. Acquired middle cranial fossa fistula: Normal pressure and nontraumatic in origin. Neurosurgery 1979 Oct;5(4):466-471. 